\title{
Carlo Tognato (ed.), Cultural agents reloaded: the legacy of Antanas Mockus
}

\author{
(2017) Harvard University Press
}

Cambridge, 646 pp.

\author{
Santiago Silva Jaramillo \\ Universidad EAFIT \\ ORCID ID 0000-0002-0228-8322 \\ ssilvaja@eafit.edu.co
}

\section{Cita recomendada:}

Silva Jaramillo, S. (2021). Carlo Tognato, Cultural agents reloaded: the legacy of Antanas Mockus. Eunomía. Revista en Cultura de la Legalidad, 21, pp. 472-474.

doi: https://doi.org/10.20318/eunomia.2021.6377

Recibido / received: 05/09/2020

Carlo Tognato trabajó durante casi una década en la construcción de este libro. Reunir los capítulos, trabajar con los autores, adelantar las entrevistas e incluso resolver asuntos financieros y editoriales complejos que el mismo Tognato reconoce en el capítulo introductorio, supuso un esfuerzo sostenido por lograr el resultado final. Cultural Agents Reloaded: The legacy of Antanas Mockus es un compendio de reflexiones sobre la carrera académica y política de Antanas Mockus, un reconocimiento crítico a sus contribuciones a las agendas públicas de cambio social y a las reflexiones sociales sobre el abordaje cultural de los problemas públicos y dilemas colectivos en América Latina.

El libro también es un compendio de las ideas asociadas al enfoque de cultura ciudadana y sus críticas más significativas. La lista de autores de los capítulos reúne colaboradores de Mockus en sus gobiernos, investigaciones y rol de consultor, pero también, académicos que reseñan, sobre todo, las perspectivas epistemológicas, las limitaciones analíticas y las discusiones prácticas sobre el cambio cultural. El texto inicia con un capítulo introductorio de Tognato, mezcla entre historia sobre el libro, reseña de sus capítulos y recolección de argumentos sobre la relevancia de Mockus para las conversaciones sobre agencia cultural. Lo sigue un ensayo fotográfico que recuerda algunas de las acciones más significativas del enfoque de cultura ciudadana 
durante las alcaldías de Mockus en Bogotá. La tercera sección recoge ensayos de diferentes autores como Doris Sommer, Henry Murraín, Gerry Mackie, Javier Sáenz Obregón, entre otros. Estos capítulos revisan algunas de las ideas que constituyen el corpus de la propuesta del enfoque de cultura ciudadana, contribuyendo con las perspectivas presentadas por la teoría de las normas sociales, los recientes avances en política pública comportamental, la relación entre vocería, acción política y el cambio cultural, e incluso la relación de la propuesta mockusiana con las preocupaciones de Adam Smith en la Teoría de los sentimientos morales.

A continuación, el libro recoge entrevistas adelantadas por Tognato a Paul Bromberg, Rocío Londoño y Efraín Sánchez, tres académicos que trabajaron con Mockus en el Instituto de Cultura y Turismo de Bogotá durante sus dos mandatos, y con el sociólogo Jon Elster, cuyos trabajos han influenciado profundamente el enfoque de cultura ciudadana. La quinta parte del libro recoge siete comentarios de otros académicos, como Marta Zambrano, Andrés Salcedo y Francisco Thoumi, entre otros, sobre el mismo libro, en particular, la introducción de Tognato. Finalmente, en la conclusión, el libro da voz al mismo Mockus, que realiza un repaso de su propia trayectoria, haciendo eco de buena parte de los capítulos del libro, respondiendo a muchas de las críticas que plantean los diferentes autores y señalando las trayectorias que le reconoce a su propuesta conceptual y práctica de cambio cultural.

Cultural Agents Reloaded: The legacy of Antanas Mokcus permite reconocer el juicio y la rigurosidad que en ocasiones acompañó las intervenciones de cambio cultural adelantadas por Mockus durante sus administraciones, pero a la vez, la influencia constante en sus decisiones de la creatividad e incluso, algunas serendipias culpables de asuntos tan paradigmáticos en su reconocimiento público como los mimos que regulaban el tráfico en Bogotá y que nacieron de una sugerencia irónica del suegro de Paul Bromberg, director del Instituto de Cultura y Turismo de Bogotá.

Ese medio camino entre compendio de discusiones académicas y debates epistemológicos y anecdotario de la trayectoria de Mockus en lógica de agente cultural, establece un equilibrio fundamental en el libro, culpable de su pertinencia, pero también, de su agradable lectura. Ofrece una ventana a la experiencia de gobierno de Mockus con una insistencia que en ocasiones se acerca a lo repetitivo. Pero también plantea los límites del enfoque con justicia y sobre la aproximación sensata, argumento principal del mismo Tognato, del poco desarrollo epistemológico de la «cultura ciudadana» como armonización de Ley, Moral y Cultura (Mockus, 2019).

La propuesta general de Mockus aborda el reto de entender las razones de lo que él mismo denomina como el "divorcio» entre los tres sistemas reguladores del comportamiento. Mirando los problemas que la sociedad colombiana enfrentaba a finales de los años ochenta, Mockus señala las dificultades para resolver dilemas colectivos en que las personas no reconocieran en sus entramados morales y culturales lo dispuesto por la Ley y que fenómenos como la violencia interpersonal, la evasión de impuestos, el incumplimiento de normas viales, la discriminación por género o etnia, entre otros muchos problemas públicos, encontraran respuesta en el enfoque de cultura ciudadana.

El enfoque se relaciona en la naturaleza de los «agentes culturales», una propuesta de la también coautora Doris Sommer, en tanto reconoce la utilización sistemática e intensificada -desde la acción pública como acción comunicativa de Habermas- del arte y la comunicación para abordar la tarea de armonización asumida por la cultura ciudadana. Lo hace también sobre la idea de «anfibios culturales» de Mockus (2019) y el papel que les reconoce como traductores de diferentes sistemas culturales y valoraciones en proyectos de vida. El agente cultural, así como el anfibio 
cultural, despeña un papel fundamental en la agenda de armonización de Ley, Moral y Cultura.

De esta manera, el libro no es tímido en sus críticas y en plantear preguntas que, aunque incómodas si la pretensión fuera el homenaje, son pertinentes en tanto el texto es, sobre todo, un esfuerzo de comprensión de un agente cultural. Es recurrente la duda sobre la aparente poca popularidad de desarrollo conceptual e incluso aplicabilidad práctica del enfoque en América Latina. Tognato señala que las dificultades para institucionalizar el enfoque pueden tener explicaciones en la asociación política que se puede hacer sobre la carrera del mismo Mockus y en el poco desarrollo que han tenido las apuestas por lograr mayor «legitimidad epistemológica» de la aproximación de cultura ciudadana.

También se abordan las limitaciones del enfoque respecto a su aplicación discontinua y las dudas sobre los resultados de algunas intervenciones. Los ensayos de Lucas Ospina y Paolo Vignolo, así como las entrevistas a Paul Bromberg y Rocío Londoño desarrollan bastante estas ideas. Las culpas se asignan sobre las mismas implicaciones políticas de los mandatos de Mockus y la manera como han concentrado la atención sobre las experiencias prácticas del enfoque. La influencia de los intereses en la política electoral de Mockus, desde sus dos alcaldías hasta sus fallidas dos campañas presidenciales, son un tema recurrente para los autores, que intentan desentrañar las contradicciones para su propuesta conceptual de su labor como político.

Pero por encima de estas cuestiones problematizadoras, el libro es una celebración de un momento particular y una forma específica de abordar las dificultades políticas colombianas de mediados de los años noventa y principios del siglo XXI. La agencia cultural de Mockus y su cultura ciudadana no pueden separarse fácilmente de los momentos en los que irrumpió en el debate nacional e influyó profundamente la manera como se entendía el papel de los políticos colombianos y las responsabilidades, particularmente educadoras y cívicas, del gobierno. Los autores ofrecen respuestas en ocasiones bastante dispares sobre el «legado mockusiano», pero nunca subestiman la importancia que su aproximación tiene para la forma como actualmente se hace política y la manera como se abordan los problemas públicos en Colombia.

Finalmente, Cultural Agents Reloaded: The legacy of Antanas Mockus sugiere tareas pendientes y perspectivas del enfoque de cultura ciudadana. Probablemente el más importante e interesante se centre sobre la posibilidad de desprenderlo un poco de la trayectoria, sobre todo política, de su principal referente. Esto es, reconocer la importancia que la cultura ciudadana puede tener como enfoque de política pública y cambio social, desprendiéndolo poco a poco, en tanto se desarrolla su propuesta epistemológica y se amplía su repertorio práctico, del protagonista del libro.

\section{Bibliografía}

Mockus, A. (2019). Convivencia como armonización entre Ley, Moral y Cultura. En: Eslava, A. (Ed.) Lo mejor de las personas. Teoría, intervención y agenda de la cultura ciudadana (21-42). Medellín: Alcaldía de Medellín - Universidad EAFIT. 